\title{
The association between metabolic syndrome and asymptomatic carotid artery stenosis in menopausal women: a cross-sectional study in a Chinese population
}

This article was published in the following Dove Press journal:

Therapeutics and Clinical Risk Management

\author{
Bin Zhu' \\ Lei Zhang ${ }^{2}$ \\ Xiao Ping Cheng ${ }^{3}$ \\ Lei Wang ${ }^{4}$ \\ Yue Tian' \\ $\mathrm{Xi} \mathrm{Xi} \mathrm{Li}^{1}$ \\ Ying Ping Liu \\ Zhi Gang Zhao' \\ 'Department of Pharmacy, Beijing \\ Tiantan Hospital Affiliated to Capital \\ Medical University, Beijing 100050, \\ China; ${ }^{2}$ Department of Pharmacy, \\ Beijing Shijitan Hospital, Capital \\ Medical University, Beijing 100050, \\ China; ${ }^{3}$ Department of Nephrology, \\ Shaanxi Hospital of Traditional \\ Chinese Medical, ShaaXi 710003 , \\ China; ${ }^{4}$ Department of Endocrinology, \\ Third Affiliated Hospital of Beijing \\ University of Chinese Medicine, \\ Beijing 100029, China; ${ }^{5}$ Obstetrics \\ Department, Beijing Obstetrics and \\ Gynecology Hospital, Capital Medical \\ University, Beijing 100026, China
}

Correspondence: Ying Ping Liu Beijing Obstetrics and Gynecology Hospital, Capital Medical University,

Beijing 100026, China

Tel +860l 06525073 I

Email yingping|@।63.com

Zhi Gang Zhao

Department of Pharmacy, Beijing Tiantan Hospital Affiliated to Capital Medical

University, Beijing 100050, China

Tel +8601067098039

Email 1022zzg@sina.com
Background: To examine the association of metabolic syndrome (MetS) with carotid artery stenosis (CAS), especially in menopausal women in China.

Materials and methods: A cross-sectional study of menopause women aged $\geq 40$ years were enrolled from the Jidong community of Tangshan City between 2013 and 2014 to examine the association between MetS and CAS. Logistic regression analyses were performed to analyze the association between MetS and the presence of CAS.

Results: A total of 762 menopause women with mean age $59.3 \pm 5.6$ years were enrolled in our analysis. Of all the people, 111 participants in CAS group $(n=159)$ and 297 participants in no CAS group $(n=603)$ were diagnosed with MetS meantime. Menopausal women with MetS had increased risk of CAS (OR, 2.383; 95\% CI, 1.639-3.464), and the association was further verified by adjusting for confounding factors (OR, 1.949; 95\% CI, 1.269-2.994). In addition, age, physical activity (never or moderate), body mass index $\left(>24 \mathrm{~kg} / \mathrm{m}^{2}\right)$, and family income $(<3,000 \mathrm{RMB})$ were independent important factors to CAS development in those with MetS. Conclusion: MetS is associated with CAS especially in women after menopause.

Keywords: metabolic syndrome, carotid artery stenosis, cross-sectional study, Jidong community, menopause

\section{Introduction}

Extracranial carotid artery stenosis (CAS), a common form of atherosclerotic vascular disease, is a major risk factor for vascular death, ischemic stroke, and myocardial infarction. ${ }^{1,2}$ It is generally prevalent in the aging population and increases with age. Epidemiological studies have demonstrated that metabolic syndrome (MetS) is an independent risk factor for CAS, especially in those over 40 years old. As a major public health problem, MetS is characterized by a clustering of risk factors, including abdominal obesity, low high-density lipoprotein (HDL) cholesterol, hypertriglyceridemia, high blood pressure, and hyperglycemia., ${ }^{3,4}$ Each of these abnormalities can lead to inflammation and fatty deposits, thus causing arterial stiffness and endothelial damage. $^{5}$

MetS exhibits a significant increase with age, especially after menopause. ${ }^{6,7}$ As one of the physiological stages in women's lives, menopause causes a decline in estrogen production leading to several significant metabolic complications, such as dyslipidemia, insulin resistance, and hypertension. ${ }^{8}$ Gurka et al reported that menopausal women 
exhibit a higher prevalence of MetS as well as a higher risk of cardiovascular disease. ${ }^{9}$ Meanwhile, Hodis et al found that the use of estrogen and sex hormone-binding globulin can decrease the risk of subclinical atherosclerosis in postmenopausal women. ${ }^{10}$ However, few studies have focused on the relationship between MetS and asymptomatic CAS in menopausal women. Thus, our aim was to investigate this association in a cross-sectional study of a northern Chinese cohort.

\section{Materials and methods Design and study population}

This was a community-based observational study aiming to investigate the epidemiological association of asymptomatic CAS with MetS among menopausal women in China. The study population was derived from the Jidong community, which mainly comprises of employees of the Jidong Oil Field, located in Tangshan in northern China, and their families. ${ }^{11-13}$ The Jidong cohort included 9,078 participants, and a total of 762 postmenopausal women over 40 years old were randomly selected between July 2013 and August 2014 for this study. The inclusion and exclusion of study participants are illustrated in Figure 1. The study was performed according to the guidelines of the Helsinki Declaration, with the approval of the Ethics Committee of the Jidong Oilfield Hospital. Written informed consent forms were obtained from all participants.

\section{Assessment of MetS}

MetS was defined as the presence of least three of the following five criteria: elevated waist circumference $(\geq 88 \mathrm{~cm})$, elevated triglycerides $(\geq 1.7 \mathrm{mmol} / \mathrm{L}$ or $\geq 150 \mathrm{mg} / \mathrm{dL})$, low HDL cholesterol $(<1.29 \mathrm{mmol} / \mathrm{L}$ or $<50 \mathrm{mg} / \mathrm{dL}$ ), hypertension (systolic blood pressure $\geq 130$ and/or diastolic blood pressure $\geq 85 \mathrm{mmHg}$ ), and impaired fasting glucose $(\geq 5.5 \mathrm{mmol} / \mathrm{L}$ or $\geq 100 \mathrm{mg} / \mathrm{dL}) .{ }^{14,15}$

\section{Assessment of CAS}

All participants underwent high-resolution B-mode ultrasonography of their extracranial arteries. All arterials scans were performed by two independent sonographers using the iU-22 system (Philips Medical Systems, Bothell, WA, USA). The sonographers were blinded to the participants' baseline information. CAS was defined according to the diagnostic criteria of the Radiological Society of North America. ${ }^{16}$ Briefly, stenosis was defined as peak systolic velocity $(P S V) \geq 125 \mathrm{~cm} / \mathrm{s}$ in the presence of an atherosclerotic lesion or a maximum diameter reduction of $\geq 50 \%$. Participants with PSV $<125 \mathrm{~cm} / \mathrm{s}$ and no signs of atherosclerotic lesions were considered to be without stenosis. ${ }^{17}$

\section{Assessment of menopause status}

All female participants were required to answer a questionnaire about their menopausal status. Postmenopausal women were defined as women who reported an absence of menstrual periods for 12 consecutive months. For women who had experienced a natural menopause, age at menopause was defined as the self-reported age at the time of the last menstruation. ${ }^{18}$ Menopause was defined as early (40-44 years), normal ( $45-50$ years), and late ( $>51$ years).

\section{Statistical analyses}

Statistical analyses were performed using SAS software, version 9.4 (SAS Institute, Cary, NC, USA). Descriptive

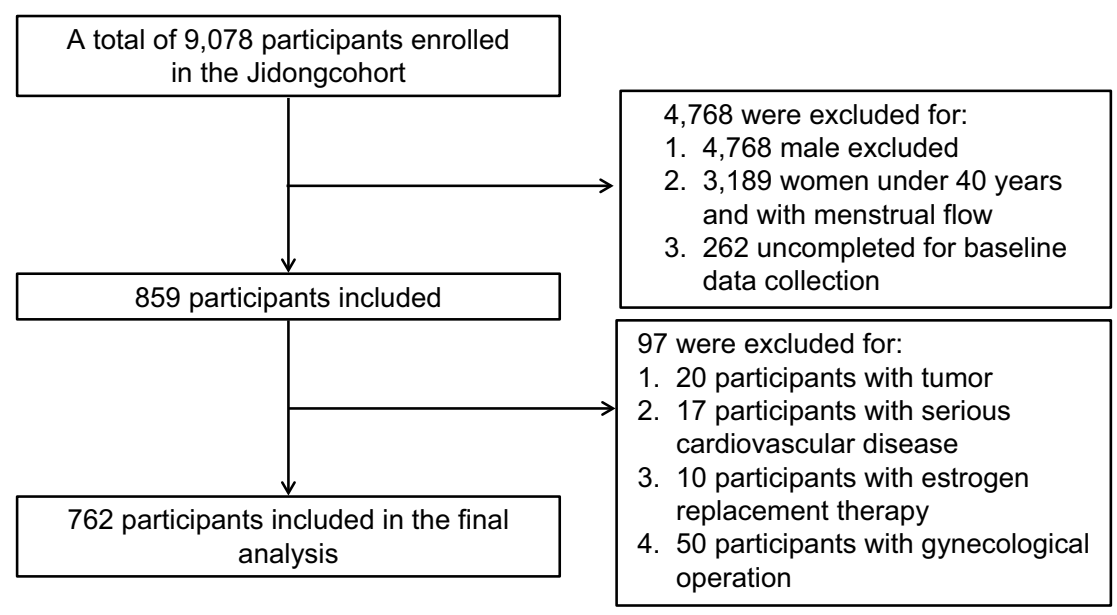

Figure I Flow chart of the enrolled participants. 
analyses were used to summarize the baseline characteristics of participants based on questionnaire and biochemical results. Continuous variables were presented as mean $\pm \mathrm{SD}$ and compared using ANOVA. Categorical variables were presented as percentages and compared using the chisquared test. Logistic regression analyses were performed to analyze the association between MetS and the presence of CAS by calculating the ORs and 95\% CIs. We adjusted for potential confounders of the risk factors for CAS in four different models: age (Model 1); age and body mass index (BMI) (Model 2); age, BMI, parity, and previous miscarriage (Model 3); age, BMI, parity, previous miscarriage, education, family income (monthly), and physical activity (Model 4). All statistical tests were two-sided, and a $P$-value $\leq 0.05$ was considered to be significant.

\section{Results}

\section{Characteristics of the study population}

A total of 762 menopause women with mean age of $59.3 \pm 5.6$ years were enrolled in the final analysis. The participant selection process is illustrated in Figure 1. There were 159 participants with CAS (average age, 59. $4 \pm 6.0$ years) and 603 (average age, 59.3 \pm 5.6 years) without CAS. Among these, 111 participants in the CAS group and 297 in the no CAS group had concurrent MetS. All participants with CAS were asymptomatic. The basic characteristics of the cohort are shown in Table 1.

A stepwise logistic regression was performed to detect any independent risk factors associated with CAS. The crude model showed that menopausal women with MetS had a greatly increased risk of CAS (OR, 2.383; 95\% CI, 1.639-3.464). After adjustment for age, BMI, parity, previous miscarriage, education, family income, and physical activity, the association remained significant (OR, 1.949; 95\% CI, 1.269-2.994) (Figure 2). In addition, stratification by age of menopause showed that the association between $\mathrm{CAS}$ and the presence of MetS was significant regardless of early, normal, or late menopause (Table 2).

To further elucidate the correlations between MetS and CAS, confounding factors, including age, physical activity,

Table I The characteristics of the participants

\begin{tabular}{|c|c|c|c|c|}
\hline Characteristics & Total, N (\%) & $\begin{array}{l}\text { No carotid artery } \\
\text { stenosis, } \mathbf{N}(\%)\end{array}$ & $\begin{array}{l}\text { Carotid artery } \\
\text { stenosis, N (\%) }\end{array}$ & $P$-value \\
\hline Number, N (\%) & 762 & $603(79.13)$ & $159(20.87)$ & \\
\hline Age & $59.3 \pm 5.6$ & $59.3 \pm 5.6$ & $59.4 \pm 6.0$ & 0.8405 \\
\hline Married (\%) & $757(99.3)$ & $599(99.3)$ & I58 (99.4) & 0.9619 \\
\hline BMI $\left(\mathrm{kg} / \mathrm{m}^{2}\right)$ & $25.2 \pm 3.4$ & $24.8 \pm 3.3$ & $26.4 \pm 3.7$ & $<0.0001$ \\
\hline Waist circumference, $\mathrm{cm}$ & $86.1 \pm 9.5$ & $85.1 \pm 9.0$ & $89.7 \pm 10.4$ & $<0.0001$ \\
\hline Diabetes, N (\%) & $103(13.5)$ & $76(12.6)$ & $27(17.0)$ & 0.1510 \\
\hline Hypertension, N (\%) & $378(49.6)$ & $291(48.3)$ & $87(54.7)$ & 0.1474 \\
\hline Dyslipidemia, N (\%) & $498(65.4)$ & $384(63.7)$ & II 4 (7I.7) & 0.0588 \\
\hline SBP (mmHg) & $135.8 \pm 20.7$ & $135.0 \pm 20.1$ & $139.1 \pm 22.6$ & 0.0262 \\
\hline $\mathrm{DBP}(\mathrm{mmHg})$ & $81.5 \pm 12.4$ & $81.0 \pm 12.0$ & $83.6 \pm 13.4$ & 0.0179 \\
\hline TG (mmol/L) & $1.7 \pm 1.2$ & $1.6 \pm 1.2$ & $1.9 \pm 1.2$ & 0.0148 \\
\hline LDL-C (mmol/L) & $2.8 \pm 0.6$ & $2.8 \pm 0.6$ & $2.9 \pm 0.6$ & 0.3498 \\
\hline HDL-C (mmol/L) & $1.3 \pm 0.3$ & $1.3 \pm 0.3$ & $1.2 \pm 0.2$ & $<0.0001$ \\
\hline Total cholesterol (mmol/L) & $5.0 \pm 1.0$ & $5.0 \pm 1.0$ & $5.0 \pm 1.0$ & 0.8131 \\
\hline Fasting blood glucose (mmol/L) & $5.6 \pm 1.5$ & $5.5 \pm 1.4$ & $5.9 \pm 1.8$ & 0.0105 \\
\hline Education level & & & & 0.9363 \\
\hline Low & $135(17.7)$ & $108(17.9)$ & $27(17.0)$ & \\
\hline Intermediate & $552(72.4)$ & $435(72.1)$ & $117(73.6)$ & \\
\hline High & $75(9.8)$ & $60(10.0)$ & $15(9.4)$ & \\
\hline Income, ¥/month, N (\%) & & & & 0.6665 \\
\hline$<¥ 3,000$ & $533(69.95)$ & $424(70.32)$ & $109(68.55)$ & \\
\hline$\geq ¥ 3,000$ & $229(30.05)$ & $179(29.68)$ & $50(31.45)$ & \\
\hline Age of menopause (years), N (\%) & & & & 0.6975 \\
\hline$\leq 45$ & $75(9.8)$ & $59(9.8)$ & $16(10.1)$ & \\
\hline $45-50$ & $358(47.0)$ & $279(46.3)$ & 79 (49.7) & \\
\hline$>52$ & $329(43.2)$ & $265(43.9)$ & $64(40.3)$ & \\
\hline
\end{tabular}


Table I (Continued)

\begin{tabular}{|c|c|c|c|c|}
\hline Characteristics & Total, N (\%) & $\begin{array}{l}\text { No carotid artery } \\
\text { stenosis, } \mathbf{N}(\%)\end{array}$ & $\begin{array}{l}\text { Carotid artery } \\
\text { stenosis, N (\%) }\end{array}$ & $P$-value \\
\hline Current smokers (\%) & $16(2.1)$ & II (I.8) & $5(3.1)$ & 0.3016 \\
\hline Current drinkers (\%) & $22(2.9)$ & $17(2.8)$ & $5(3.1)$ & 0.8274 \\
\hline Physical activity (yes, \%) & & & & 0.0056 \\
\hline Never or moderate & $260(34.1)$ & $191(31.7)$ & $69(43.4)$ & \\
\hline Heavy & $502(65.9)$ & $412(68.3)$ & $90(56.6)$ & \\
\hline Parity & & & & 0.1805 \\
\hline 0 or 1 & 377 (49.48) & $306(50.75)$ & $71(44.65)$ & \\
\hline 2 & $292(38.32)$ & $221(36.65)$ & $71(44.65)$ & \\
\hline$\geq 3$ & $93(12.20)$ & $76(12.60)$ & $17(10.69)$ & \\
\hline Miscarriage (yes, \%) & & & & 0.9189 \\
\hline 0 & $350(46.4)$ & $274(45.9)$ & $76(48.1)$ & \\
\hline I & $213(28.2)$ & $169(28.3)$ & $44(27.8)$ & \\
\hline 2 & $147(19.5)$ & $119(19.9)$ & $28(17.7)$ & \\
\hline$\geq 3$ & $45(6.0)$ & $35(5.9)$ & $10(6.3)$ & \\
\hline Metabolic syndrome disease & & & & $<0.0001$ \\
\hline No & $354(46.5)$ & $306(50.7)$ & $48(30.2)$ & \\
\hline Yes & $408(53.5)$ & $297(49.3)$ & III (69.8) & \\
\hline
\end{tabular}

Notes: Data are shown as mean $\pm \mathrm{SD}$, or median (interquartile range), or $\mathrm{n}(\%)$ where indicated; Compared with no carotid artery stenosis group, $P<0.05$ means difference was statistically significant.

Abbreviations: BMI, body mass index; HDL-C, high-density lipoprotein cholesterol; LDL-C, low-density lipoprotein cholesterol; TG, triglyceride.

BMI, and family income, were investigated by logistic regression. Compared with those without MetS, postmenopausal women with MetS were more likely to develop CAS ( $\leq 50$ years, OR, $1.81 ; 95 \%$ CI, $1.045-3.136$; $>50$ years, OR, 2.125; 95\% CI, 1.034-4.368). In addition, physical activity (never or moderate), BMI $\left(>24 \mathrm{~kg} / \mathrm{m}^{2}\right)$, and family income $(<3,000 \mathrm{RMB})$ were also independent risk factors for CAS development in women with MetS (Table 3).

\section{Discussion}

Menopause is a cascade of physiological and psychological change involving sex hormone levels, hemodynamics, and oxidative stress whose complex effect on the endocrine system may lead to long-term implications for women's health including dyslipidemia, insulin resistance, and hypertension. ${ }^{8}$ These changes make postmenopausal women significantly more susceptible to MetS. ${ }^{19}$ Arthur et al had found that the prevalence of MetS increased with an overall prevalence of $30.4 \%$ in postmenopausal women. ${ }^{20}$ Maiello et al had discovered that nearly $66.4 \%$ postmenopausal women have had MetS. ${ }^{21}$ Our results are in accordance with previous studies with MetS found in $53.5 \%$ of our population. Postmenopausal women affected by MetS have an increased aortic stiffness, which is associated with CAS and is an important marker of early atherosclerosis and high risk of stroke.

The individual abnormalities involved in MetS are traditional risk factors for cardiovascular disease. Epidemiological studies have demonstrated that postmenopausal women are at a higher risk of MetS. Our community-based study showed that MetS is significantly associated with CAS in postmenopausal women. In addition, our results also showed that there was no correlation between age at menopause and the development of CAS in women with MetS.

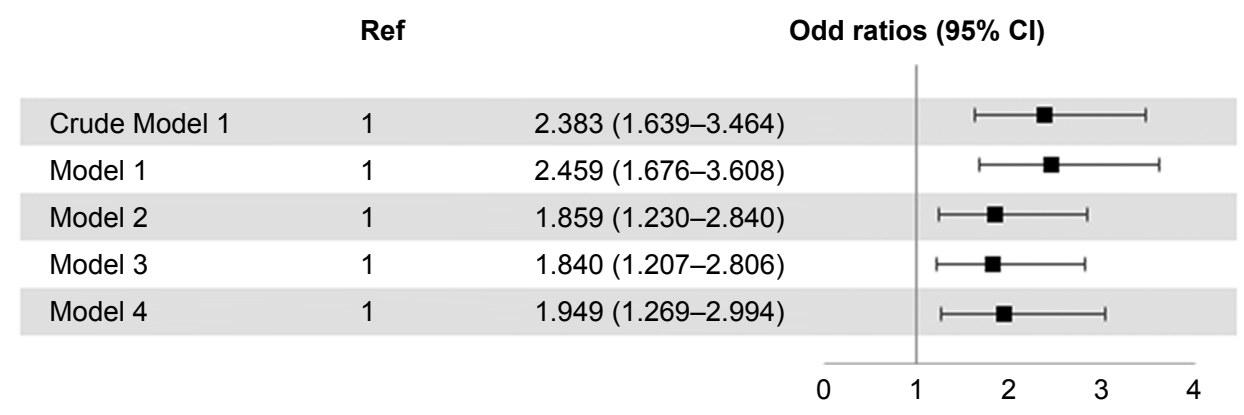

Figure 2 The association between carotid artery stenosis and MetS. Abbreviation: MetS, metabolic syndrome. 
Table 2 Multivariable analyses of relationship between CAS and MetS stratified by age

\begin{tabular}{|c|c|c|c|c|}
\hline \multirow[t]{2}{*}{ Models } & \multirow[t]{2}{*}{ Ref } & Age $<45$ years & 45 years $\leq$ Age $\leq 50$ years & Age $>50$ years \\
\hline & & OR (95\% Cl) & OR $(95 \% \mathrm{Cl})$ & OR (95\% Cl) \\
\hline Crude model & 1 & $3.917(1.219-12.583)$ & $2.238(1.343-3.730)$ & $2.742(1.570-4.786)$ \\
\hline Model I & 1 & $3.678(1.092-12.390)$ & $2.224(\mathrm{I} .329-3.72 \mathrm{I})$ & $3.054(1.720-5.424)$ \\
\hline Model 2 & 1 & $5.04 \mathrm{I}(1.230-20.66)$ & $2.347(1.376-4.004)$ & $3.033(I .68 I-5.470)$ \\
\hline Model 3 & 1 & $7.432(|.437-38.43|)$ & $2.359(1.357-4.100)$ & $3.05 \mathrm{I}(1.677-5.553)$ \\
\hline
\end{tabular}

Notes: Crude model, unadjusted; Model I, adjust for BMI; Model 2, model 2 with additional adjustment for parity and miscarriage; Model 3 , model 3 with additional adjustment for education, family income, and physical activity.

Abbreviations: BMI, body mass index; CAS, carotid artery stenosis; MetS, metabolic syndrome.

The reason several risk factors for CAS are clustered together in patients with MetS has not yet been determined. Two or more cardiovascular risk factors were found more frequently; hypertension and lipid abnormalities, which are associated with elevated cardiovascular risk, were found in $80.5 \%$ and $91.8 \%$ of participants with MetS in our study, respectively. ${ }^{22}$ The results suggest that a simple clinical evaluation for the presence of MetS should play a key role in CAS prevention.

In this community-based observational study, we compared CAS prevalence in postmenopausal women with and without MetS. The results showed that women with MetS had a higher CAS prevalence even after adjusting for risk factors (age, BMI, parity, previous miscarriage, education, family income, and physical activity). In addition, it was noteworthy that family income was significantly correlated with the development of CAS, which had not been mentioned in previous reports. We believe this maybe a reflection of the participants' socioeconomic conditions. As people with low family incomes may have less access to physical training and periodic physical examinations, their risk of CAS may be increased. In addition, we should also note that patients with CAS tended to be younger. We speculate that this may be related to the environment, lifestyle, and diet among other factors.

A few limitations of the current study are acknowledged. First, this was a cross-sectional study and might be affected by reverse causality and survivor bias. We had excluded the participants with serious cardiovascular and cerebrovascular diseases from the analysis. Therefore, determining the outcomes of the relationship in question was not possible. Second, this was a cohort study in which the participants were not matched by age at its baseline. Therefore, the results may have been biased. Furthermore, our results cannot be generalized to all Asian women as the participants, employees, retirees, and relatives of persons associated with the Jidong coal mine industry do not represent a typical Asian population. Third, CAS was defined as PSV $\geq 125 \mathrm{~cm} / \mathrm{s}$, which may reflect the presence of calcific lesions but overlook soft or lipoid lesions. Fourth, in addition to the small sample size, the number of participants at each period of menopause (early, normal, and late) was not equal across the subgroups.

Table 3 The logistic regression analyses of age, physical activity, BMI, and family income to the development of CAS in those with MetS

\begin{tabular}{|c|c|c|c|}
\hline \multirow[t]{2}{*}{ Characteristics } & \multicolumn{2}{|c|}{ Carotid artery stenosis } & \multirow{2}{*}{$\begin{array}{l}P \text {-value for } \\
\text { interaction }\end{array}$} \\
\hline & $\begin{array}{l}\text { Without } \\
\text { MetS }\end{array}$ & $\begin{array}{l}\text { MetS } \\
(95 \% \mathrm{CI})\end{array}$ & \\
\hline Age (years) & & & 0.4635 \\
\hline$\leq 50$ & Ref & $1.810(1.045-3.136)$ & \\
\hline$>50$ & Ref & 2.125 (1.034-4.368) & \\
\hline Physical activity & & & 0.9079 \\
\hline Never or moderate & Ref & 2.165 (1.107-4.232) & \\
\hline Heavy & Ref & I.7I8 (0.967-3.05I) & \\
\hline BMI $\left(\mathrm{kg} / \mathrm{m}^{2}\right)$ & & & 0.1269 \\
\hline$\leq 24$ & Ref & I. I 46 (0.533-2.466) & \\
\hline$>24$ & Ref & $2.470(1.409-4.330)$ & \\
\hline Income & & & 0.0002 \\
\hline$<3,000$ & Ref & 3.557 (1.995-6.340) & \\
\hline$\geq 3,000$ & Ref & $0.980(0.93 \mathrm{I}-1.032)$ & \\
\hline
\end{tabular}

Note: Data are OR $(95 \% \mathrm{Cls})$.

Abbreviations: BMI, body mass index; CAS, carotid artery stenosis; MetS, metabolic syndrome. 


\section{Conclusion}

In conclusion, the finding that menopausal women with MetS are more susceptible to CAS is clinically significant. Hypertension and lipid abnormalities can be significant risk factors during disease progress. The effect of MetS on cardiovascular disease should be taken into consideration in order to prevent cardiovascular and cerebrovascular diseases, especially in postmenopausal women.

\section{Acknowledgments}

This study was supported by China Postdoctoral Science Foundation (No 2017M620700), the Natural Science Foundation of China (No 81803909) and Beijing Municipal Administration of Hospitals' Youth Programme (QML20170703). The authors appreciate all the participants and their relatives in the study and the members of the survey teams from the Jidong community.

\section{Author contributions}

All authors contributed toward data analysis, drafting and critically revising the paper, gave final approval of the version to be published, and agree to be accountable for all aspects of the work.

\section{Disclosure}

The authors report no conflicts of interest in this work.

\section{References}

1. Aday AW, Beckman JA. Medical management of asymptomatic carotid artery stenosis. Prog Cardiovasc Dis. 2017;59(6):585-590.

2. Truong VV, Abou-Chebl A. Interventional management of asymptomatic extracranial carotid stenosis. Curr Cardiol Rep. 2011;13(1):30-37.

3. He SJ, Chan C, Xie ZD, et al. The relationship between serum uric acid and metabolic syndrome in premenopausal and postmenopausal women in the Jinchang Cohort. Gynecol Endocrinol. 2017;33(2):141-144.

4. Samson SL, Garber AJ. Metabolic syndrome. Endocrinol Metab Clin North Am. 2014;43(1):1-23.

5. Martens FM, van der Graaf Y, Dijk JM, Olijhoek JK, Visseren FL. Carotid arterial stiffness is marginally higher in the metabolic syndrome and markedly higher in type 2 diabetes mellitus in patients with manifestations of arterial disease. Atherosclerosis. 2008;197(2):646-653.

6. Sharma S, Aggarwal N, Joshi B, Suri V, Badada S. Prevalence of metabolic syndrome in pre- and post-menopausal women: a prospective study from apex institute of North India. J Midlife Health. 2016;7(4):169-174.
7. Iglseder B, Cip P, Malaimare L, Ladurner G, Paulweber B. The metabolic syndrome is a stronger risk factor for early carotid atherosclerosis in women than in men. Stroke. 2005;36(6):1212-1217.

8. Montalcini T, Gorgone G, Gazzaruso C, Sesti G, Perticone F, Pujia A. Carotid atherosclerosis associated to metabolic syndrome but not BMI in healthy menopausal women. Diabetes Res Clin Pract. 2007; 76(3):378-382.

9. Gurka MJ, Vishnu A, Santen RJ, Deboer MD. Progression of metabolic syndrome severity during the menopausal transition. J Am Heart Assoc. 2016;5(8): e003609.

10. Hodis HN, Mack WJ, Lobo RA, et al. Estrogen in the prevention of atherosclerosis. A randomized, double-blind, placebo-controlled trial. Ann Intern Med. 2001;135(11):939-953.

11. Song Q, Liu X, Wang A, et al. Associations between non-traditional lipid measures and risk for type 2 diabetes mellitus in a Chinese community population: a cross-sectional study. Lipids Health Dis. 2016;15:70.

12. Han X, Yang Y, Chen Y, et al. Association between insomnia and atrial fibrillation in a Chinese population: a cross-sectional study. Clin Cardiol. 2017;40(9):765-769.

13. Hao Z, Zhang Y, Li Y, et al. The association between ideal cardiovascular health metrics and extracranial carotid artery stenosis in a northern Chinese population: a cross-sectional study. Sci Rep. 2016;6:31720.

14. Banegas JR, López-García E, Dallongeville J, et al. Achievement of lipoprotein goals among patients with metabolic syndrome at high cardiovascular risk across Europe. The EURIKA study. Int J Cardiol. 2013;166(1):210-214.

15. Wang A, Wu L, Liu X, et al. The prevalence of carotid plaque with different stability and its association with metabolic syndrome in China: The Asymptomatic Polyvascular Abnormalities Community study. Medicine. 2016;95(34):e4619.

16. Grant EG, Benson CB, Moneta GL, et al. Carotid artery stenosis: grayscale and Doppler US diagnosis - Society of Radiologists in Ultrasound Consensus Conference. Radiology. 2003;229(2):340-346.

17. Ben-Shoshan J, Zahler D, Steinvil A, et al. Extracranial carotid artery stenosis and outcomes of patients undergoing transcatheter aortic valve replacement. Int J Cardiol. 2017;227:278-283.

18. Muka T, Asllanaj E, Avazverdi N, et al. Age at natural menopause and risk of type 2 diabetes: a prospective cohort study. Diabetologia. 2017;60(10):1951-1960.

19. Dong S, Peng Z, Tao Y, Huo Y, Zhou H. Metabolic syndrome is associated with increased risk of short-term post-procedural complications after carotid artery stenting. Neurol Sci. 2017;38(11):1933-1939.

20. Arthur FK, Adu-Frimpong M, Osei-Yeboah J, Mensah FO, Owusu L. The prevalence of metabolic syndrome and its predominant components among pre-and postmenopausal Ghanaian women. BMC Res Notes. 2013;6:446.

21. Maiello M, Zito A, Ciccone MM, Palmiero P. Metabolic syndrome and its components in postmenopausal women living in southern Italy, Apulia region. Diabetes Metab Syndr. 2017;11(1):43-46.

22. Brunzell JD, Davidson M, Furberg CD et al. Lipoprotein management in patients with cardiometabolic risk: consensus statement from the American Diabetes Association and the American College of Cardiology Foundation. Diabetes Care. 2008;31(4):811-822.
Therapeutics and Clinical Risk Management

\section{Publish your work in this journal}

Therapeutics and Clinical Risk Management is an international, peerreviewed journal of clinical therapeutics and risk management, focusing on concise rapid reporting of clinical studies in all therapeutic areas, outcomes, safety, and programs for the effective, safe, and sustained use of medicines. This journal is indexed on PubMed Central, CAS,

\section{Dovepress}

EMBase, Scopus and the Elsevier Bibliographic databases. The manuscript management system is completely online and includes a very quick and fair peer-review system, which is all easy to use. Visit $\mathrm{http}: / /$ www.dovepress.com/testimonials.php to read real quotes from published authors. 